\section{Pembelajaran Gelombang, Bunyi, dan Cahaya Berbantuan Office Suite dan Penjelajah Internet}

\author{
Sparisoma Viridi ${ }^{1}$, Tati Kristianti ${ }^{2}$, Jam'ah Halid $^{1}$, \\ Lintang Ratri Prastika ${ }^{4}$ \\ ${ }^{1}$ Prodi Fisika, FMIPA, Institut Teknologi Bandung \\ Jalan Ganesha 10, Bandung 40132, Indonesia \\ ${ }^{2}$ OpenLab Salman ITB \\ Jalan Ganesha 7, Bandung 40132, Indonesia \\ ${ }^{3}$ Lembaga Pengembangan Pendidikan Salman ITB \\ Jalan Ganesha 7, Bandung 40132, Indonesia \\ ${ }^{4}$ SEAMEO QITEP in Science \\ Jalan Diponegoro 12, Bandung 40115, Indonesia \\ ${ }^{1}$ dudung@gmail.com, ${ }^{2}$ jhalidwae@gmail.com, \\ ${ }^{3}$ kristianti007@yahoo.com, ${ }^{4}$ lintang.r.prastika@gmail.com \\ DOI: 10.17605/OSF.IO/MHXVC
}

Generasi saat ini, yang telah sejak kecil berinteraksi dengan komputer dan internet, tidak serta-merta handal dalam mencari informasi terutama apabila terkait materi pembelajaran sehingga para peserta ajar masih perlu diarahkan (Viridi et al., 2017a). Dan dalam rangka untuk mempersiapkan generasi $Z$ yang unik tersebut, selain dengan menggunakan eksperimen (Viridi et al., 2017b), para pengajar perlu pula dibekali kemampuan untuk membuat bahan pembelajaran yang berbasiskan bahasa dari generasi tersebut, yaitu sesuatu yang terkait dengan piranti lunak dan internet. Untuk para pengajar yang sudah agak berumur perlu diperhatikan hambatan yang mungkin dapat ditemui (Gatto \& Tak, 2008), apabila dibandingkan dengan yang berumur lebih muda. Hal lain yang perlu diperhatikan adalah bahwa computer dan internet dapat pula memiliki dampak negatif yang tidak diinginkan, seperti adanya indikasi kecanduan apabila digunakan secara berlebihan (Griffiths, 2000).

Penggunaan komputer dalam pembelajaran fisika telah lama dilakukan, akan tetapi harus benar-benar ditelaah dengan baik karena dapat menghasilkan efek positif atau tidak sama sekali (Redish, 1993). Dengan demikian piranti lunak yang fleksibel dan dapat diatur sesuai keinginan adalah yang tepat, karena pengajar dapat merangkaikannya dengan kebutuhan pembelajaran, minat pengajar, dan pendekatan pedagogi yang sesuai (Esquembre, 2002). Terlepas dari pendekatan yang digunakan dalam pembelajaran, baik menggunakan komputer ataupun tidak, fisika sayangnya merupakan bidang yang membuat peserta ajar tidak termotivasi (Valiati \& Heineck, 2002). Namun demikian, animo untuk pemanfaatkan komputer untuk pembelajaran fisika meningkat, terutama karena dapat mengakomodasi eksperimen virtual yang aman dan murah dalam mengajarkan suatu konsep, sampai-sampai satu nomor terbitan suatu jurnal terkemuka telah didedikasikan untuk tulisan-tulisan terkait hal ini, yang menggambarkan bagaimana 'e-science' menjadi suatu alat baru yang kuat dan amat berperan penting dalam pembelajaran sains (Botet \& Trizac, 2005).

Dalam pembelajaran gelombang, bunyi, dan cahaya yang dibahas di sini suatu office suite yang umumnya terdiri dari program pengolah kata, spreadsheet, dan presentasi (Wikipedia, 2017a), e.g. Microsoft Office dan suatu penjelajah internet (Wikipedia, 2017b), e.g. Google Chrome akan digunakan. Untuk yang kedua, fiturnya untuk menjalankan JavaScript (JS) yang dibutuhkan. JS dapat dikatakan merupakan bahasa pemrograman web yang digunakan dalam mayoritas situs web dan penjelajah internet moderen, sehingga komputer, konsol game, tablet, dan smart phone mengikutsertakan JS (Flanagan, 2011). Dengan demikian tidak lagi perlu proses instalasi piranti lunak pemrograman khusus apabila hendak menjalankan JS, sejauh telah ada suatu penjelajah internet (yang umumnya telah interinstal) dalam komputer yang digunakan. Dan untuk suatu office suite umumnya juga telah ada. Dengan demikian dua piranti lunak yang digunakan umumnya telah tersedia pada komputer. Microsoft Excel sebagai suatu spreadsheet merupakan contoh piranti lunak yang telah banyak dimanfaatkan sebagai media pembelajaran, misalnya materi kinematika (Nuroso \& Arifin, 2011) dan gelombang (Nafis, 2015), sedangkan untuk JS, yang masih kurang favorit, telah pula digunakan untuk materi e-learning mekanika (Leonop \& Suhendra, 2011).

Gelombang merupakan perambatan energi, dengan energi yang dimaksud adalah getaran. Dengan demikian agar dapat muncul gelombang perlu terdapat getaran sebagai sumber gelombang. Terdapat banyak getaran di sekeliling kita seperti membran yang bergetar (pada bedug) merupakan sumber gelombang bunyi, senar yang diketuk (atau dipetik) pada suatu posisinya merupakan sumber bagi perambatan gelombang pada tali (senar), kaki yang digerak-gerakkan dalam air saat seseorang duduk di pinggir kolam renang merupakan sumber bagi perambatan gelombang pada air, dan lainlainya. Sumber bunyi, untuk saat ini, dibatasi yang hanya disebabkan oleh gerak harmonis sederhana (GHS), sehingga kinematikanya dapat dinyatakan oleh (Takács \& Rohal'-Ilkiv, 2012)

$$
q(t)=A_{q} \sin \left(\omega t+\phi_{0}\right)
$$

dengan amplitudo $q_{A}$, frekuensi angular $\omega$, dan fasa awal $\phi_{0}$, serta $q$ adalah suatu besaran fisis tertentu, seperti contohnya simpangan $y$ pada gelombang tali, tinggi permukaan air $h$ pada gelombang air, dan perbedaan tekanan udara $\Delta p$ pada gelombang bunyi. Besaran yang dilambangkan oleh $q$ tersebut merupakan besaran yang berubah-ubah nilainya dengan waktu $t$ mengikuti Persamaan (1). Saat $q$ yang berada pada posisi $x$ berubah, umumnya gangguan tersebut dirambatkan pada medium di sebelahnya pada posisi $x+d x$ 
sehingga $q$ pada tempat tersebut juga berubah. Demikian seterusnya sehingga pada sembarang tempat $x$ dapat dituliskan kinematika dari $q$ dalam bentuk

$$
q(x, t)=A_{q} \sin \left(\omega t+\phi_{0}-k x\right)
$$

yang dikenal sebagai fungsi gelombang (Cresser, 2005). Persamaan (1) tidak lain menggambarkan sumber dari Persamaan (2) yang terletak pada $x=0$. Dalam Persamaan (2) terdapat bilangan gelombang $k$, yang bersama-sama dengan panjang gelombang $\lambda$, frekuensi $f$, periode $T$, dan laju rambat gelombang $v$ memiliki hubungan-hubungan

$$
\begin{gathered}
k=\frac{2 \pi}{\lambda}, \\
\omega=\frac{2 \pi}{T}, \\
v=\frac{\omega}{k}=\frac{\lambda}{T}=\lambda f .
\end{gathered}
$$

Periode $T$ menggambarkan keberulangan dalam domain temporal (waktu) sedangkan $\lambda$ menggambarkan keberulangan dalam domain spasial (ruang).
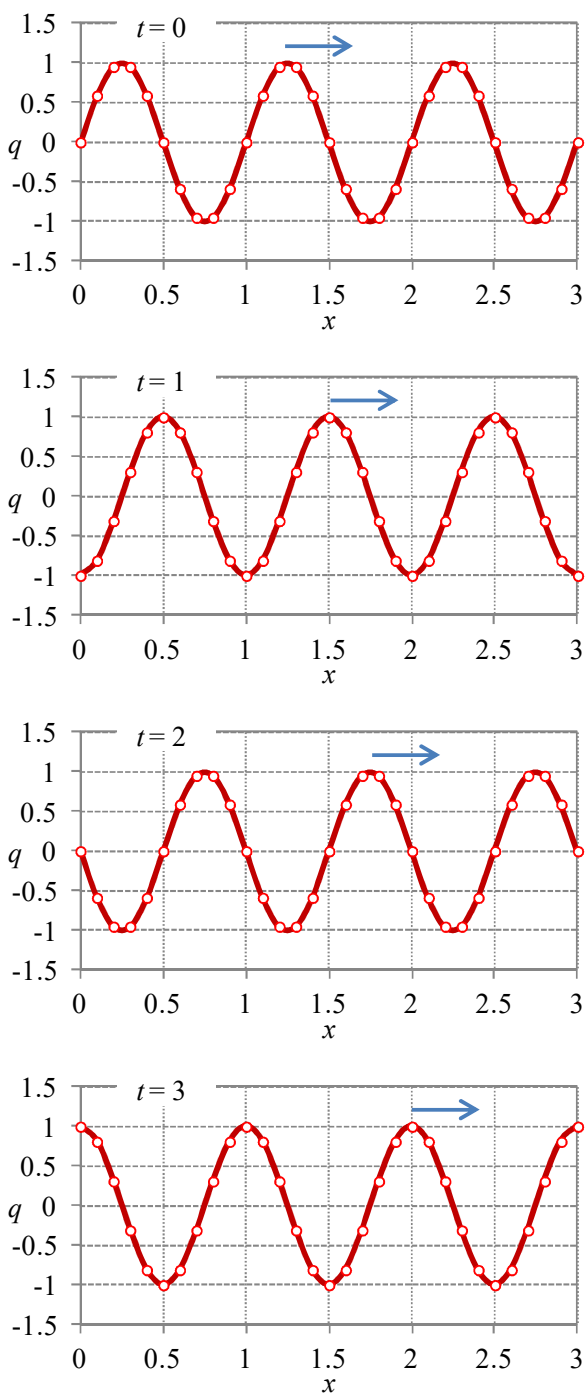

Gambar 1. Gerak gelombang $q_{A}=1, T=4 \mathrm{~s}, \lambda=1 \mathrm{~m}, \phi_{0}=\pi$ untuk waktu-waktu $t=0,1,2$, dan 3 dengan menggunakan Persamaan (2).
Dengan menggunakan Microsoft Excel dapat dibuah Gambar 1 yang menunjukkan perambatan gelombang ke arah kanan $(x+)$, yang letak sel-selnya disajikan dalam Gambar 2.

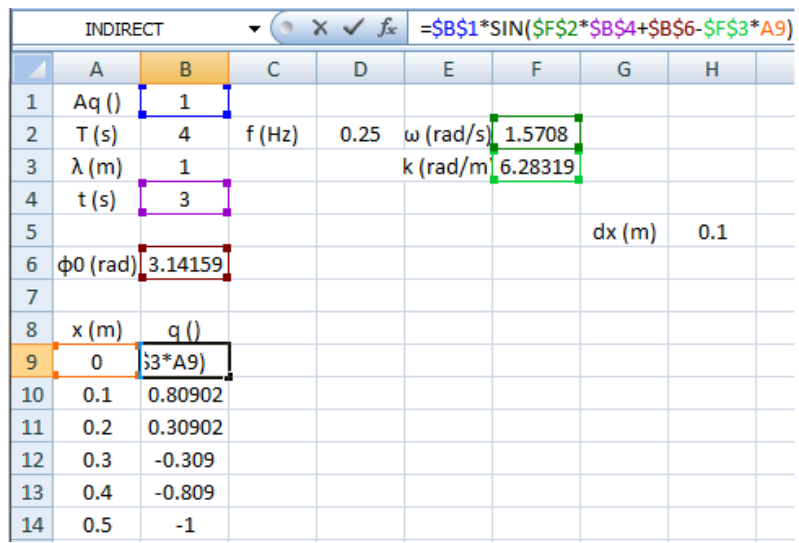

Gambar 2. Tata letak sel-sel Excel untuk menggambarkan perambatan gelombang.

Antara sel-sel A1 sampai F3 hubungannya diberikan oleh Persamaan (3)-(5), sedangkan penerapan Persamaan (2) terdapat pada sel B9 sampai B39. Perhatikan bahwas saat $t=4 \mathrm{~s}$ (tidak disajikan) gelombang akan memberikan hasil seperti saa $t=0 \mathrm{~s}$ dikarenakan periodenya adalah $T=4$. Ingat bahwa untuk sembarang getaran atau gelombang berlaku bahwa

$$
q(x, t+T)=q(x, t+T)
$$

dan

$$
q(x+\lambda, t)=q(x, t) .
$$

Berkas spreadsheet dalam Gambar 2 dapat diunduh dari https://osf.io/3btsm/.

Soal 1. Coba modifikasi spreadsheet dalam Gambar 2 sehingga dapat menggambarkan gelombang yang merambat ke kiri $(x-)$ dengan terlebih dahulu memperhatikan sel B9 dan sel-sel yang terkait, lalu mengubahnya.

Salah satu jenis gelombang yang menarik untuk dibahas adalah gelombang stasioner atau gelombang berdiri, yang merupakan hasil superposisi dari gelombang yang merambat ke kanan dan ke kiri atau secara sederhananya bila gelombang yang merambat ke kanan adalah

$$
q_{+}(x, t)=A_{q} \sin \left(\omega t+\phi_{0}-k x\right)
$$

dan gelombang yang merambat ke kiri adalah

$$
q_{-}(x, t)=A_{q} \sin \left(\omega t+\phi_{0}+k x\right),
$$

maka gelombang stasioner yang dapat dibentuk keduanya adalah

$$
q_{s}(x, t)=q_{+}(x, t)+q_{-}(x, t),
$$

yang akan memberikan hasil

$$
q_{s}(x, t)=2 A_{q} \sin \left(\omega t+\phi_{0}\right) \cos (k x) .
$$

Soal 2. Tunjukkan bahwa Persamaan (11) memang dapat diperoleh dari Persamaan (10). Dan bila Persamaan (8) dan (9) yang merupakan fungsi gelombang, adalah solusi dari persamaan gelombang, tunjukkan bahwa Persamaan (11) juga merupakan solusi dari persamaan gelombang. 
Persamaan (8) dan (9) merupakan fungsi gelombang yang merupakan solusi dari persamaan gelombang

$$
\frac{\partial^{2} q}{\partial x^{2}}-\frac{1}{v^{2}} \frac{\partial^{2} q}{\partial t^{2}}=0
$$

dan demikian pula dengan Persamaan (11).
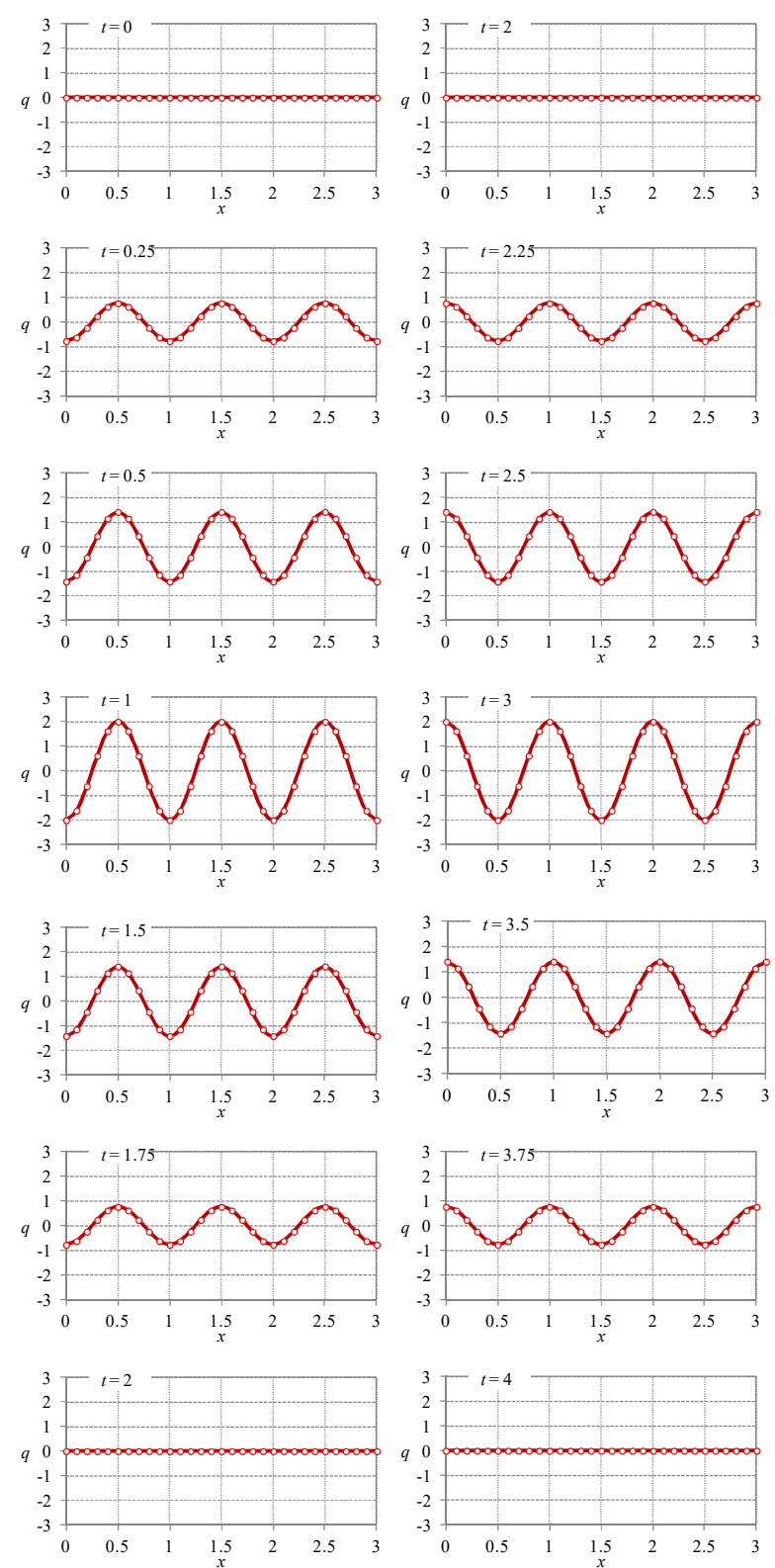

Gambar 3. Gelombang stasioner dengan nilai-nilai parameter gelombang yang merambat ke kanan dan ke kiri sama seperti dalam Gambar 1.

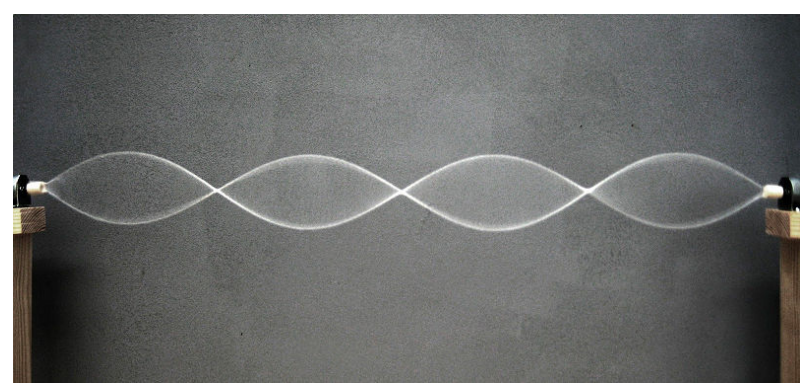

Gambar 4. Bentuk gelombang stasioner saat suatu tali digetarkan (Patel, 2014).

Umumnya pemahaman peserta ajar mengenai bentuk gelombang stasioner adalah seperti dalam Gambar 4 yang terjadi karena gerak tali yang cukup cepat sehingga mata manusia tidak dapat mengikutinya. Peristiwa yang sebenarnya terjadi adalan seperti dalam Gambar 3. Sebagai catatan, dalam Gambar 3 posisi node bukan berada pada ujung-ujung karena syarat batas belum diterapkan, sedangkan pada Gambar 4 syarat batas telah digunakan.

\begin{tabular}{|c|c|c|c|c|c|c|c|c|}
\hline \multicolumn{3}{|c|}{ INDIRECT } & \multicolumn{2}{|c|}{$-0 \times \checkmark f x$} & $=\mathrm{B} 9+\mathrm{C} 9$ & \multirow[b]{2}{*}{$\mathrm{F}$} & \multirow[b]{2}{*}{ G } & \multirow[b]{2}{*}{ H } \\
\hline 4 & A & B & C & D & E & & & \\
\hline 1 & $\mathrm{Aq}()$ & 1 & & & & & & \\
\hline 2 & $T(s)$ & 4 & $\mathrm{f}(\mathrm{Hz})$ & 0.25 & $\omega(\mathrm{rad} / \mathrm{s})$ & 1.5708 & & \\
\hline 3 & $\lambda(\mathrm{m})$ & 1 & & & $\mathrm{k}(\mathrm{rad} / \mathrm{m})$ & 6.28319 & & \\
\hline 4 & $t(s)$ & 1 & & & & & & \\
\hline 5 & & & & & & & $\mathrm{dx}(\mathrm{m})$ & 0.1 \\
\hline 6 & $\phi 0$ (rad) & 3.14159 & & & & & & \\
\hline 7 & & & & & & & & \\
\hline 8 & $x(m)$ & $q+()$ & $q-()$ & qs () & & & & \\
\hline 9 & 0 & -1 & -1 & $=\mathrm{B} 9+\mathrm{C} 9$ & & & & \\
\hline 10 & 0.1 & -0.809 & -0.809 & -1.618 & & & & \\
\hline 11 & 0.2 & -0.309 & -0.309 & -0.618 & & & & \\
\hline 12 & 0.3 & 0.30902 & 0.30902 & 0.61803 & & & & \\
\hline 13 & 0.4 & 0.80902 & 0.80902 & 1.61803 & & & & \\
\hline 14 & 0.5 & 1 & 1 & 2 & 2 & & & \\
\hline
\end{tabular}

Gambar 5. Tata letal sel-sel yang menghasilkan Gambar 3.

Isi sel B9 adalah sama seperti dalam Gambar 2, yaitu $=\$ B \$ 1 * \operatorname{SIN}(\$ F \$ 2 * \$ B \$ 4+\$ B \$ 6-\$ F \$ 3 * \$ 9)$ yang bersumber dari Persamaan (8), sedangkan isi sel C9 adalah $=\$ B \$ 1 * \operatorname{SIN}(\$ F \$ 2 * \$ B \$ 4+\$ B \$ 6+\$ F \$ 3 A 9)$, yang menggambarkan Persamaan (9). Keduanya berbeda pada tanda sebelum \$F\$3. Selanjutnya sel D9 merepresentasikan Persamaan (10), yang secara numerik akan sama dengan Persamaan (11).

Soal 3. Jelaskan bagaimana hubungan antar amplitudo gelombang stasioner yang terbentuk dengan amplitudo masing-masing gelombang pembentuknya yang bersuperposisi. Lihatlah sumbu vertikal dari Gambar 1 dan 3.

Selanjutnya apabila berbicara mengenai bunyi maka hal yang menarik adalah bagaimana membuat visualisasi dari perbedaan tekanan udara yang juga memenuhi Persamaan (2).

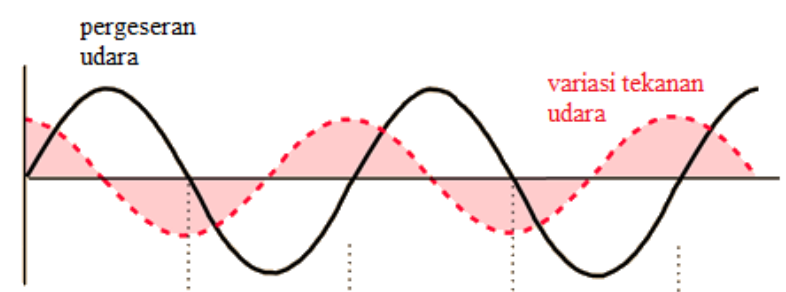

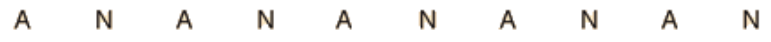

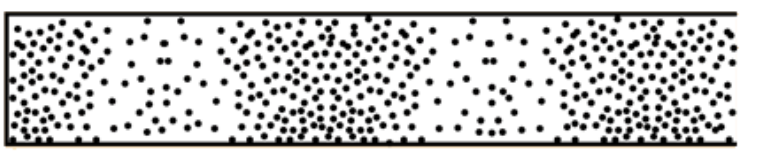

Gambar 6. Ilustrasi variasi tekanan udara dan pergeseran molekul-molekul udara dalam suatu pipa suara dengan titik-titik antinode (A) dan node (N) tekanannya (Nave, 2016a).

Pada ujung kiri, di mana terdapat dinding, tidak terdapat perubahan fasa saat pemantulan karena gelombang menghadapi impedansi akustik yang lebih besar (oleh karena itu terdapat antinode tekanan), sedangkan pada ujung kiri yang terbuka terjadi perubahan fasa 
sebesar $\pi$ diakibatkan gelombang bertemu medium dengan impedansi akustik lebih rendah (sehingga terdapat node tekanan).

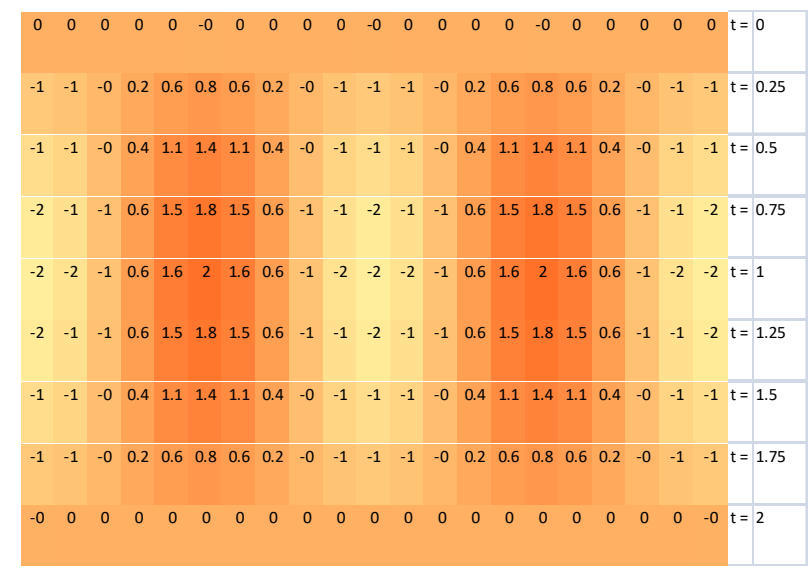

Gambar 7. Gelombang stasioner tekanan untuk sistem pipa suara dengan kedua ujung tertutup untuk waktu setengah periode, di mana rentang warna tekanannya adalah terendah tertinggi.

Tekanan bernilai nol berarti sama dengan tekanan udara luar atau $p_{0}$, tekanan positif berarti lebih besar dari $p_{0}$, tekanan negatif berarti lebih rendah dari $p_{0}$. Bila pada dinding terdapat tekanan lebih dari $p_{0}$ berarti saat itu molekul udara tidak dapat bergeser (karena adanya dinding) sehingga memberikan tekanan balik yang besar.

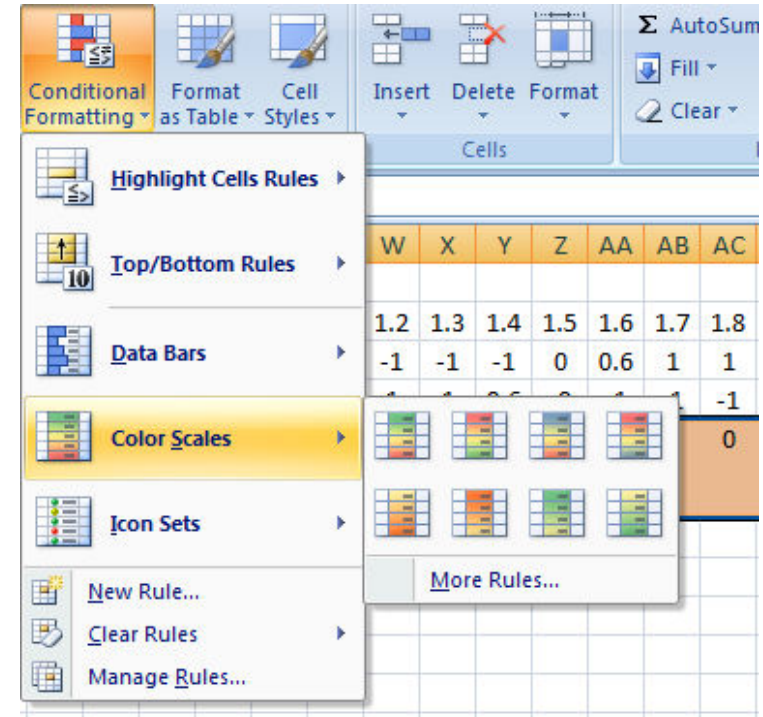

Gambar 8. Fitur Conditional Formatting yang dapat mewarnai sel sesuai dengan angka yang terdapat dalam sel tersebut.

Warna-warna tersebut dapat diperoleh dalam spreadsheet Microsoft Excel dengan menggunakan fitur Conditional Formatting sebagaimana ditunjukkan dalam Gambar 8.

Soal 4. Lakukan latihan untuk memahirkan pemanfaatan fitur Conditional formatting dan ubah-ubah rentang warna yang ingin digunakan.

Konsep lain mengenai bunyi yang menarik untuk disinggung adalah efek Doppler, yang merupakan efek yang muncul saat baik sumber bunyi atapun pendengar saling bergerak relatif sehingga mengubah frekuensi yang terdengar, yang dirumuskan dalam bentuk (Fowler, 2009)

$$
f_{p}=f_{s}\left(\frac{v \pm u_{p}}{v \mp u_{s}}\right),
$$

dengan frekuensi yang terdengar pengamat $f_{p}$, frekuensi sumber bunyi $f_{s}$, laju rambat bunyi $v$, kecepatan pengamat $u_{p}$, dan kecepatan sumber bunyi $u_{s}$. Frekuensi yang terdengar oleh pengamat akan lebih besar dari frekuensi sumber bunyi bila jarak antar pengamat dan sumber bunyi semakin kecil dan sebaliknya. Tabel 1 memberikan sembilan kemungkinan yang dapat terjadi.

Tabel 1 Nilai $u_{s}$ dan $u_{p}$ serta pengaruhnya terhadap $f_{p} / f_{s}$.

\begin{tabular}{|c|c|c|c|c|c|c|c|c|}
\hline Kasus & & & sera & & & $u_{p}$ & $u_{s}$ & $f_{p} / f_{s}$ \\
\hline 1 & $\leftarrow$ & $p$ & $\leftarrow$ & $\mathrm{s}$ & & $<0$ & $<0$ & $\sim 1$ \\
\hline 2 & $\leftarrow$ & $p$ & & $\mathrm{~s}$ & & $<0$ & 0 & $<1$ \\
\hline 3 & $\leftarrow$ & $p$ & & $\mathrm{~s}$ & $\rightarrow$ & $<0$ & $>0$ & $<1$ \\
\hline 4 & & $p$ & $\leftarrow$ & $\mathrm{s}$ & & 0 & $<0$ & $>1$ \\
\hline 5 & & $p$ & & $\mathrm{~s}$ & & 0 & 0 & 1 \\
\hline 6 & & $p$ & & $\mathrm{~s}$ & $\rightarrow$ & 0 & $>0$ & $<1$ \\
\hline 7 & $\rightarrow$ & $p$ & $\leftarrow$ & $\mathrm{s}$ & & $>0$ & $<0$ & $>1$ \\
\hline 8 & $\rightarrow$ & $p$ & & $\mathrm{~s}$ & & $>0$ & 0 & $>1$ \\
\hline 9 & $\rightarrow$ & $p$ & & $\mathrm{~s}$ & $\rightarrow$ & $>0$ & $>0$ & $\sim 1$ \\
\hline
\end{tabular}

Ilustrasi dalam Tabel 1 adalah untuk letak pengamat ( $p$ ) berada di sebelah kiri dan sumber bunyi (s) berada di sebelah kanan, sesuai dengan letaknya dalam kolom kedua yang menggambarkan arah gerak dan $\left|u_{s}\right|=$ $\left|u_{p}\right|$. Bila $\left|u_{s} / u_{p}\right| \neq 1$ perlu ditelaah dulu gerak relatif di antara $\mathrm{p}$ dan $\mathrm{s}$, apakah saling menjauh atau mendekat. Pada udara kering bertemperatur $0{ }^{\circ} \mathrm{C}$ laju rambat udara adalah $331.2 \mathrm{~m} / \mathrm{s}$ (Wikipedia, 2017c), yang untuk temperatur lebih tinggi dalam kelembaban yang sama (0\%) dapat didekati oleh

$$
v=(3.31 .2+0.606 \theta)
$$

\begin{tabular}{|c|c|c|c|c|c|c|c|}
\hline \multicolumn{3}{|c|}{ SUM } & $-\circlearrowleft \times \checkmark f_{x}$ & \multicolumn{4}{|c|}{$=\$ E \$ 3^{*}(\$ B \$ 2+B 6) /(\$ B \$ 2+C 6)$} \\
\hline 4 & A & B & C & D & E & $\mathrm{F}$ & \\
\hline 1 & $\theta\left({ }^{\circ} \mathrm{C}\right)$ & 0 & & $\mathrm{up}(\mathrm{m} / \mathrm{s})$ & 30 & & \\
\hline 2 & $\mathrm{v}(\mathrm{m} / \mathrm{s})$ & 331.2 & & us $(\mathrm{m} / \mathrm{s})$ & 20 & & \\
\hline 3 & & & & fs $(H z)$ & 150 & & \\
\hline 4 & & & & & & & \\
\hline 5 & Kasus & up & us & $\mathrm{fp}$ & $\mathrm{fp} / \mathrm{fs}$ & & \\
\hline 6 & 1 & -30 & -20 & $3 \$ 2+C 6)$ & 0.97 & & \\
\hline 7 & 2 & -30 & 0 & 136.41 & 0.91 & & \\
\hline 8 & 3 & -30 & 20 & 128.64 & 0.86 & & \\
\hline 9 & 4 & 0 & -20 & 159.64 & 1.06 & & \\
\hline 10 & 5 & 0 & 0 & 150.00 & 1.00 & & \\
\hline 11 & 6 & 0 & 20 & 141.46 & 0.94 & & \\
\hline 12 & 7 & 30 & -20 & 174.10 & 1.16 & & \\
\hline 13 & 8 & 30 & 0 & 163.59 & 1.09 & & \\
\hline 14 & 9 & 30 & 20 & 154.27 & 1.03 & & \\
\hline 15 & & & & & & & \\
\hline
\end{tabular}

dengan $\theta$ adaah temperatur dalam ${ }^{\circ} \mathrm{C}$ dan $v$ dalam $\mathrm{m} / \mathrm{s}$.

Gambar 9. Tabel dalam spreadsheet untuk menghitung $f_{p} / f_{s}$ menggunakan Persamaan (13)-(14). 
Soal 5. Modifikasi spreadsheet dalam Gambar 9 dengan terlebih dahulu mengunduhnya dari https://osf.io/3btsm/.

Dengan memanfaatkan Tabel 1 dapat dibuat soal-soal yang sama mekanisme penyelesaiannya akan tetapi berbeda nilai-nilai variabelnya. Jenis soal-soal seperti ini dapat mengakomodasi peserta ajar untuk saling bekerja sama dalam mendiskusikan hasilnya dan bukan jawabannya. Dengan menggunakan JS dapat diperoleh hasil seperti dalam Gambar 10.

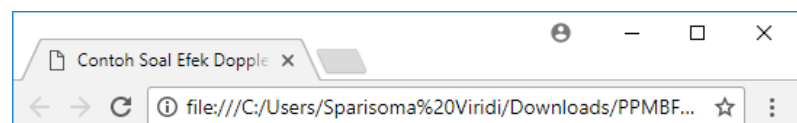

\section{Efek Doppler}

Soal 1. Pengamat $p$ yang berada di sebelah kiri sumber bunyi $s$ bergerak dengan kecepatan $u_{p}=10.00 \mathrm{~m} / \mathrm{s}$ dengan sumber bunyi yang berada di sebelah kanannya sedang bergerak dengan kecepatan $u_{s}=-10.00 \mathrm{~m} / \mathrm{s}$. Bila frekuensi sumber bunyi $f_{s}=500.00 \mathrm{~Hz}$ tentukanlah frekuensi yang terdengar pengamat $f p$

Jawab 1. Efek Doppler diberikan oleh

$$
f_{p}=f_{s} \frac{v \pm u_{p}}{v \mp u_{s}} .
$$

Dengan menggunakan Persamaan (1) dapat diperoleh bahwa frekuensi yang terdengar oleh pengamat $f_{p}=531.13 \mathrm{~Hz}$

Gambar 10. Contoh soal efek Doppler dengan menggunakan HTML dan JS.

Adapun untuk menghasilkan tampilan dalam Gambar 10 tersebut diperlukan kode berikut yang tersimpan dalam berkas bernama doppler1.html (yang dapat diunduh di https://osf.io/59wv2/files/).

$<$ DOCTYPE html>

$$
<\text { ! - - }
$$

dopplerl.html

Example of physics problem related to Doppler efect

created using HTML and JavaScript

Sparisoma Viridi | dudung@gmail.com

20171207

Create this HTML.

$$
-->
$$

$<$ html $>$

$<$ head $>$

<script type="text/x-mathjax-config">

MathJax.Hub.Config ( \{

TeX: \{ equationNumbers: \{ autoNumber: "AMS" \}

\}) ;

$</$ script $>$

<script type="text/x-mathjax-config">

MathJax.Hub.Config ( \{

tex2jax: \{inlineMath: [ ['\$','\$'],

$[' \backslash \backslash(', ' \backslash \backslash) ']]\}$

\}) ;

$</$ script $>$

<script type="text/javascript" async

src="https://cdnjs.cloudflare.com/ajax/libs/mat hjax/2.7.2/MathJax.js?config=TeX-MML-AM_CHTML">

\section{$</$ script $>$}

<title>Contoh Soal Efek Doppler</title>

$</$ head $>$

$<$ body $>$

$<$ script $>$

// Define global variables

$\operatorname{var} \mathrm{T}=0 ; / / \mathrm{OC}$

var $\mathrm{V}=(331.2+0.06 * \mathrm{~T}) ; / / \mathrm{m} / \mathrm{s}$

$\operatorname{var} \mathrm{fs}=500 ; / / \mathrm{Hz}$

var up $=10 ; / / \mathrm{m} / \mathrm{s}$

var us $=-10 ; / / \mathrm{m} / \mathrm{s}$

$\operatorname{var} \mathrm{fp}=\mathrm{fs} *(\mathrm{v}+\mathrm{up}) /(\mathrm{v}+\mathrm{us})$;

// Write value to html

function out(x, name, unit) \{

var $\mathrm{xx}=\mathrm{x}$.toFixed (2);

var str = name $+"="+x x+"$ " + unit;

document.write (str);

\}

$</$ script $>$

$<$ h1 $>$ Efek Doppler $</$ hl $>$

$<\mathrm{p}>$

$<\mathrm{b}>$ Soal $1</ \mathrm{b}>$. Pengamat $\$ \mathrm{p} \$$ yang berada $\mathrm{di}$ sebelah kiri sumber bunyi $\$ s \$$ bergerak dengan kecepatan <script>out (up, "\$u p\$",

"m/s") $;</$ script $>$ dengan sumber bunyi yang berada di sebelah kanannya sedang bergerak dengan kecepatan <script>out(us, "\$u_s\$", "m/s") $;</$ script $>$. Bila frekuensi sumber bunyi <script>out (fs, "\$f s\$", "Hz") ; </script>

tentukanlah frekuensi yang terdengar pengamat \$fp .

$</ \mathrm{p}>$

$<\mathrm{p}>$

$<\mathrm{b}>$ Jawab $1</ \mathrm{b}>$. Efek Doppler diberikan oleh $</ \mathrm{p}>$

$\backslash$ begin \{equation \}

$\mathrm{f} \_\mathrm{p}=\mathrm{f} \_\mathrm{s} \backslash \mathrm{frac}\left\{\mathrm{v} \backslash \mathrm{pm} \mathrm{u} \_p_{-}\left\{\mathrm{v} \backslash \mathrm{mp} \mathrm{u}_{-} \mathrm{s}\right\}\right.$.

$\backslash$ label \{eq: Doppler-effect

lend \{equation \}

$<\mathrm{p}>$

Dengan menggunakan Persamaan leqref eq: Dopplereffect\} dapat diperoleh bahwa frekuensi yang terdengar oleh pengamat <script>out (fp,

"\$f_p\$", "Hz") $;</$ script $>$.

$</ \mathrm{p}>$

$</$ body $>$

$</$ html $>$

Fitur berikutnya yang dapat ditambahkan adalah membuat soalnya menjadi dinamis dengan memanfaatkan fungsi Math. random () yang terdapat dalam JS sehingga bilangan bulat dengan rentang tertentu dapat dibangkitkan melalu fungsi randInt (min, max). Lengkapnya 
isi berkas doppler2.html (yang dapat diunduh di https://osf.io/59wv2/files/) adalah sebagai berikut ini $<$ DOCTYPE html>

$<!--$

doppler2.html

Example of physics problem related to Doppler effect

created using HTML and JavaScript (random)

Sparisoma Viridi | dudungegmail.com

20171207

Create this HTML by advancing dopplerl.html with

randInt(min, max) from mjgauss.html.

$$
-->
$$

$<$ html $>$

$<$ head $>$

<script type="text/x-mathjax-config">

MathJax.Hub.Config ( \{ \}

TeX: \{ equationNumbers: \{ autoNumber: "AMS" \}

\});

$</$ script $>$

<script type="text/ $\mathrm{x}$-mathjax-config">

MathJax.Hub.Config( \{

tex2jax: \{inlineMath: [ ['\$','\$'], $[' \backslash \backslash(', ' \backslash \backslash) ']]\}$

\});

$</$ script $>$

$<$ script type="text/javascript" async

src="https://cdnjs.cloudflare. com/ajax/libs/mat hjax/2.7.2/MathJax.js?config=TeX-MML-AM_CHTML">

$</$ script $>$

$<$ script $>$

// Generate a random number in [min, max]

function randInt (min, $\max )\{$

$\operatorname{var} l e n=\max -\min +1$;

var num $=$ min + parseInt (Math.random () * len);

return num;

\}

$</$ script $>$

<title>Contoh Soal Efek Doppler</title>

$</$ head $>$

$<$ body $>$

<script>

// Define global variables

$\operatorname{var} \mathrm{T}=\operatorname{randInt}(0,25) ; / / \mathrm{oC}$

$\operatorname{var} \mathrm{V}=(331.2+0.06 * \mathrm{~T}) ; / / \mathrm{m} / \mathrm{s}$

$\operatorname{var} \mathrm{fs}=\operatorname{randInt}(200,300) ; / / \mathrm{Hz}$

var up $=\operatorname{randInt}(-20,20) ; / / \mathrm{m} / \mathrm{s}$

var us $=\operatorname{randInt}(-20,20) ; / / \mathrm{m} / \mathrm{s}$

$\operatorname{var} \mathrm{fp}=\mathrm{fs} *(\mathrm{v}+\mathrm{up}) /(\mathrm{v}+\mathrm{us})$;

// Write value to html

function out(x, name, unit, digit) \{

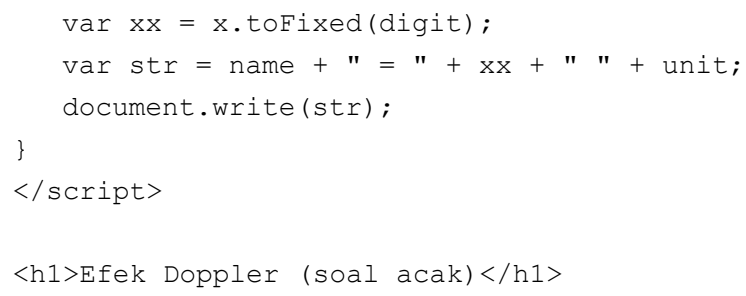

yang dapat menghasilkan Gambar 11 dengan nilai-nilai variabelnya diberikan dalam Tabel 2.

Tabel 2 Contoh-contoh nilai acak untuk soal efek Doppler.

\begin{tabular}{cccccc}
\hline Acak & $\mathrm{T}\left({ }^{\circ} \mathrm{C}\right)$ & $f_{s}(\mathrm{~Hz})$ & $u_{p}(\mathrm{~m} / \mathrm{s})$ & $u_{s}(\mathrm{~m} / \mathrm{s})$ & $\begin{array}{c}\text { Hasil } \\
f_{p}(\mathrm{~Hz})\end{array}$ \\
\hline 1 & 14 & 278 & 1 & -13 & 290.20 \\
2 & 17 & 285 & 17 & -7 & 306.03 \\
3 & 8 & 260 & 12 & 8 & 263.06 \\
4 & 9 & 203 & -18 & 15 & 183.68 \\
\hline
\end{tabular}

Dari kode JS dalam doppler2.html dapat dilihat pada bagian

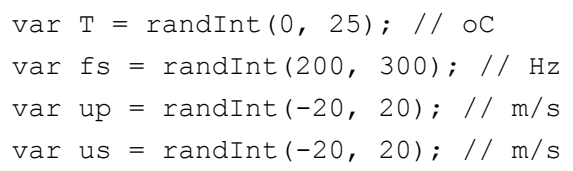

yang menunjukkan rentang nilai-nilai dari $T, f_{s}, u_{p}$, dan $u_{s}$ yang mungkin dimunculkan. Nilai-nilai $v$ dan $f_{p}$ dihitung dengan menggunakan Persamaan (14) dan (13). 


\section{Efek Doppler (soal acak)}

Soal 1. Pengamat $p$ yang berada di sebelah kiri sumber bunyi $s$ bergerak dengan kecepatan $u_{p}=1 \mathrm{~m} / \mathrm{s}$ dengan sumber bunyi yang berada di sebelah kanannya sedang bergerak dengan kecepatan $u_{s}=-13 \mathrm{~m} / \mathrm{s}$. Lingkungan merupakan udara kering dengan temperatur $T=14^{\circ} \mathrm{C}$. Bila frekuensi sumber bunyi $f_{s}=278 \mathrm{~Hz}$ tentukanlah frekuensi yang terdengar pengamat $f p$.

Jawab 1. Efek Doppler diberikan oleh

$$
f_{p}=f_{s} \frac{v \pm u_{p}}{v \mp u_{s}} .
$$

Dengan menggunakan Persamaan (1) dapat diperoleh bahwa frekuensi yang terdengar oleh pengamat $f_{p}=290.20 \mathrm{~Hz}$.

\section{Efek Doppler (soal acak)}

Soal 1. Pengamat $p$ yang berada di sebelah kiri sumber bunyi $s$ bergerak dengan kecepatan $u_{p}=17 \mathrm{~m} / \mathrm{s}$ dengan sumber bunyi yang berada di sebelah kanannya sedang bergerak dengan kecepatan $u_{s}=-7 \mathrm{~m} / \mathrm{s}$. Lingkungan merupakan udara kering dengan temperatur $T=17^{\circ} \mathrm{C}$. Bila frekuensi sumber bunyi $f_{s}=285 \mathrm{~Hz}$ tentukanlah frekuensi yang terdengar pengamat $f p$.

Jawab 1. Efek Doppler diberikan oleh

$$
f_{p}=f_{s} \frac{v \pm u_{p}}{v \mp u_{s}} .
$$

Dengan menggunakan Persamaan (1) dapat diperoleh bahwa frekuensi yang terdengar oleh pengamat $f_{p}=306.03 \mathrm{~Hz}$.

\section{Efek Doppler (soal acak)}

Soal 1. Pengamat $p$ yang berada di sebelah kiri sumber bunyi $s$ bergerak dengan kecepatan $u_{p}=12 \mathrm{~m} / \mathrm{s}$ dengan sumber bunyi yang berada di sebelah kanannya sedang bergerak dengan kecepatan $u_{s}=8 \mathrm{~m} / \mathrm{s}$. Lingkungan merupakan udara kering dengan temperatur $T=8^{\circ} \mathrm{C}$. Bila frekuensi sumber bunyi $f_{s}=260 \mathrm{~Hz}$ tentukanlah frekuensi yang terdengar pengamat $f p$.

Jawab 1. Efek Doppler diberikan oleh

$$
f_{p}=f_{s} \frac{v \pm u_{p}}{v \mp u_{s}} .
$$

Dengan menggunakan Persamaan (1) dapat diperoleh bahwa frekuensi yang terdengar oleh pengamat $f_{p}=263.06 \mathrm{~Hz}$.

\section{Efek Doppler (soal acak)}

Soal 1. Pengamat $p$ yang berada di sebelah kiri sumber bunyi $s$ bergerak dengan kecepatan $u_{p}=-18 \mathrm{~m} / \mathrm{s}$ dengan sumber bunyi yang berada di sebelah kanannya sedang bergerak dengan kecepatan $u_{s}=15 \mathrm{~m} / \mathrm{s}$. Lingkungan merupakan udara kering dengan temperatur $T=9^{\circ} \mathrm{C}$. Bila frekuensi sumber bunyi $f_{s}=203 \mathrm{~Hz}$ tentukanlah frekuensi yang terdengar pengamat $f p$.

Jawab 1. Efek Doppler diberikan oleh

$$
f_{p}=f_{s} \frac{v \pm u_{p}}{v \mp u_{s}} .
$$

Dengan menggunakan Persamaan (1) dapat diperoleh bahwa frekuensi yang terdengar oleh pengamat $f_{p}=183.68 \mathrm{~Hz}$.

Gambar 11. Contoh soal efek Doppler dengan menggunakan HTML dan JS yang nilai-nilai variabelnya telah diacak.

Soal 6. Ubahlah doppler2.html sehingga dapat dibuat jenis soal yang lain, misalnya ditanyakan temperatur $T$, frekuensi pendengar $f_{p}$, kecepatan sumber bunyi $u_{s}$, kecepatan pendengar $u_{p}$, atau variasi lainnya.
Kemampuan JS untuk bersifat dinamis dapat juga digunakan untuk menggambar, sehingga setiap saat nilai yang muncul akan bersifat acak. Salah satu visualiasi sederhana yang dapat dibuat adalah mengenai hukum Snell untuk pembiasan (Wikipedia, 2017d)

$$
\frac{\sin \theta_{1}}{\sin \theta_{2}}=\frac{n_{2}}{n_{1}}
$$

dengan $\theta_{1}$ adalah sudut sinar datang, $\theta_{2}$ adalah sudut sinar bias, $n_{1}$ adalah indeks bias medium asal sinar datang, dan $n_{2}$ adalah indeks bias medium tempat sinar dibiaskan.

\section{Hukum Snell (soal acak)}

Soal 1. Medium dari mana sinar datang memiliki indeks biar $n_{1}=1$ dan medium ke mana sinar dibiaskan memiliki indeks bias $n_{1}=1.20$. Gambarkan jalannya sinar saat melewati batas medium bila sudut datangnya adalah $\theta_{1}=52^{\circ}$.

Jawab 1. Hukum Snell menvatakan bahwa

$$
\frac{\sin \theta_{1}}{\sin \theta_{2}}=\frac{n_{2}}{n_{1}} .
$$

Dengan menggunakan Persamaan (1) dapat diperoleh sudut bias adalah $\theta_{2}=41.05^{\circ}$.

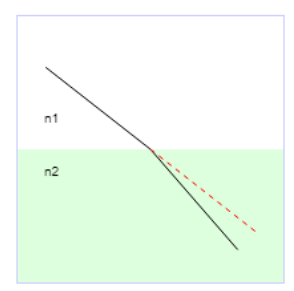

\section{Hukum Snell (soal acak)}

Soal 1. Medium dari mana sinar datang memiliki indeks biar $n_{1}=1$ dan medium ke mana sinar dibiaskan memiliki indeks bias $n_{1}=1.70$. Gambarkan jalannya sinar saat melewati batas medium bila sudut datangnya adalah $\theta_{1}=21^{\circ}$.

Jawab 1. Hukum Snell menyatakan bahwa

$$
\frac{\sin \theta_{1}}{\sin \theta_{2}}=\frac{n_{2}}{n_{1}} .
$$

Dengan menggunakan Persamaan (1) dapat diperoleh sudut bias adalah $\theta_{2}=12.17^{\circ}$.

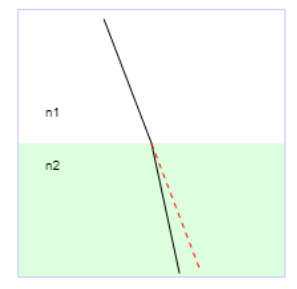

Gambar 12. Contoh soal hukum Snell dengan menggunakan HTML dan JS yang nilai-nilai variabelnya telah diacak.

Untuk menghasilkan Gambar 12 diperlukan setidaknya kode berikut ini

$<$ DOCTYPE html>

$<!--$

snalli.html

Example of physics problem related to Snell's law

created using HTML and JavaScript (random)

Sparisoma Viridi | dudung@gmail.com

20171207

Create this HTML by advancing doppler2.html with

randInt (min, max) from mjgauss.html. 


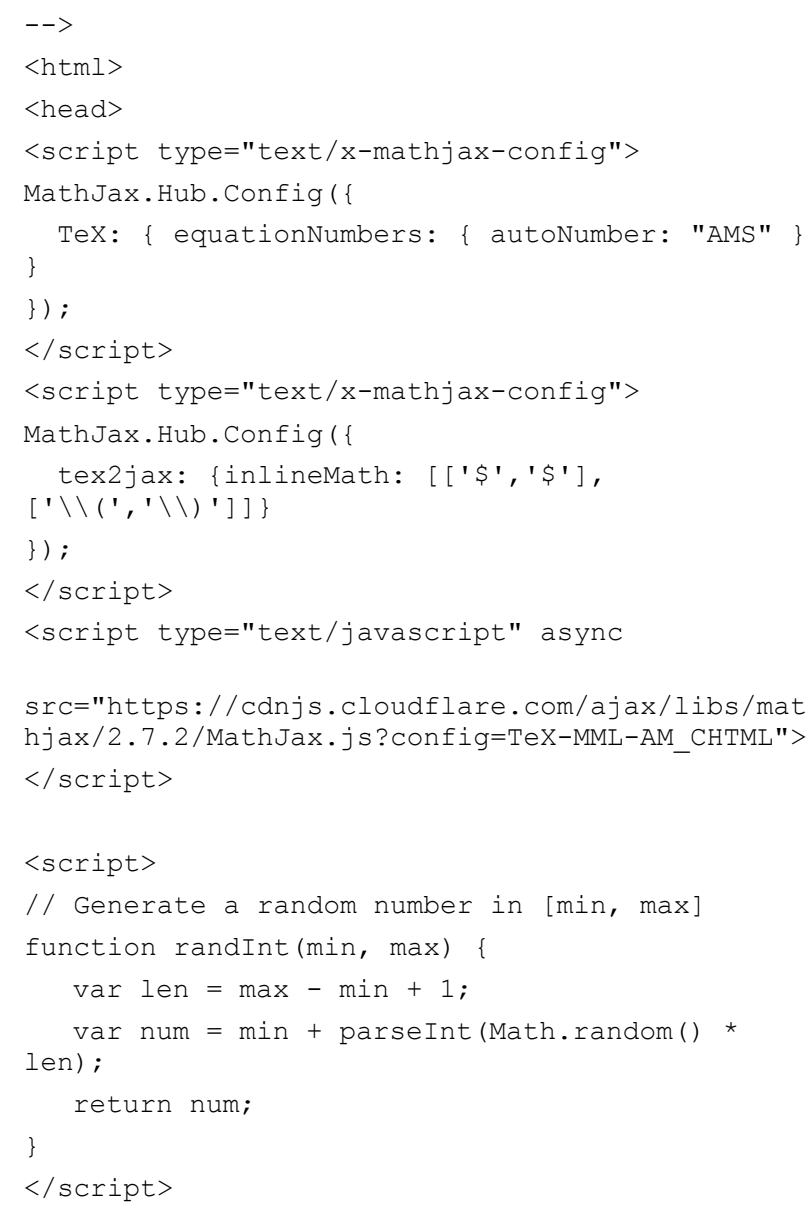

datangnya adalah <script>out (thetal, "\$\&theta;_1\$", "\&deg;", 0);</script $>$. $</ \mathrm{p}>$

$<\mathrm{p}>$

$<\mathrm{b}>$ Jawab $1</ \mathrm{b}>$. Hukum Snell menyatakan bahwa $</ \mathrm{p}>$

$\backslash$ begin \{equation \}

$\backslash$ frac $\{\backslash \sin \backslash$ theta_1 $\{\backslash \sin \backslash$ theta_2 $\}=$ $\backslash$ frac $\left\{\mathrm{n}_{-} 2\right\}\left\{\mathrm{n}_{-} 1\right\}$.

$\backslash$ label $\{$ eq: Snell-law

lend \{equation \}

\section{$<\mathrm{p}>$}

Dengan menggunakan Persamaan leqref eq:Snelllaw dapat diperoleh sudut bias adalah

<script>out (theta2, "\$\&theta;_2\$", "\&deg;", 2) $;</$ script $>$.

$</ \mathrm{p}>$

$<$ p style="text-align: center;">

<canvas id="gambar" width="200px"

height="200px" style="border: 1px solid \#ccf;">

$</$ canvas $>$

$</ \mathrm{p}>$

$<$ script $>$

var $\mathrm{c}=$ document.getElementById("gambar");

var $\mathrm{cx}=\mathrm{c}$.getContext ("2d");

cx.fillstyle = "\#dfd";

cx.fillRect $(0,100,200,200)$;

cx.fillstyle = "\#000";

cx.fillext("n1", 20, 80);

cx.filltext("n2", 20, 120);

$\operatorname{var} \mathrm{R}=100$;

$\operatorname{var} \times 1=R$ * Math.sin(thetal * Math.PI / 180);

var $\mathrm{y} 1=\mathrm{R}$ * Math.cos (thetal * Math.PI / 180);

$\operatorname{var} \times 2=R *$ Math.sin(theta2 * Math.PI / 180);

var $\mathrm{y} 2=\mathrm{R}$ * Math. cos (theta2 * Math.PI / 180);

cx.beginPath ();

cx.moveTo $(100,100)$;

cx.lineTo $(100-\mathrm{x} 1,100-\mathrm{y} 1)$;

cx.stroke ();

cx.beginPath ();

cx.moveTo $(100,100)$;

cx.lineTo $(100+\mathrm{x} 2,100+\mathrm{y} 2)$;

cx.stroke ();

Cx.setLineDash ([4, 4]);

cx.strokestyle = "\#f00";

cx.beginPath ();

cx.moveTo $(100,100)$;

cx.lineTo $(100+\mathrm{x} 1,100+\mathrm{y} 1)$;

cx.stroke ();

console. $\log (x 1)$;

console. $\log (y 1)$;

console. $\log (\mathrm{x} 2)$;

console. $\log (y 2)$; 
yang tersimpan dalam berkas snell1. html (dan dapat diunduh di https://osf.io/59wv2/files/).

Soal 7. Ubahlah snell2.html sehingga dapat dimanfaatkan untuk menghitung sudut kritis dengan syarat $n_{1}>n_{2}$. Apa syarat yang harus diperhatikan agar tidak terjadi kesalahan saat menghitung arc sin?

Fenomena lain yang menarik untuk dikaji adalah interferensi oleh dua celah sempit yang posisi-posisi angularnya untuk interferensi kostruktif diberikan oleh

$$
d \sin \theta=n \lambda, \quad n=0,1,2, \ldots,
$$

dan untuk interferensi destruktif diberikan oleh

$$
d \sin \theta=\left(n+\frac{1}{2}\right) \lambda, \quad n=0,1,2, \ldots .
$$

Ekspresi dalam Persamaan (15) diperoleh dengan asumsi bahwa sumber cahaya terletak pada jarak yang jauh, lebih jauh dibandingkan dengan jarak antar kedua celah, dan jarak antar kedua celah jauh lebih besar dari lebar celah (Nave, 2016b).

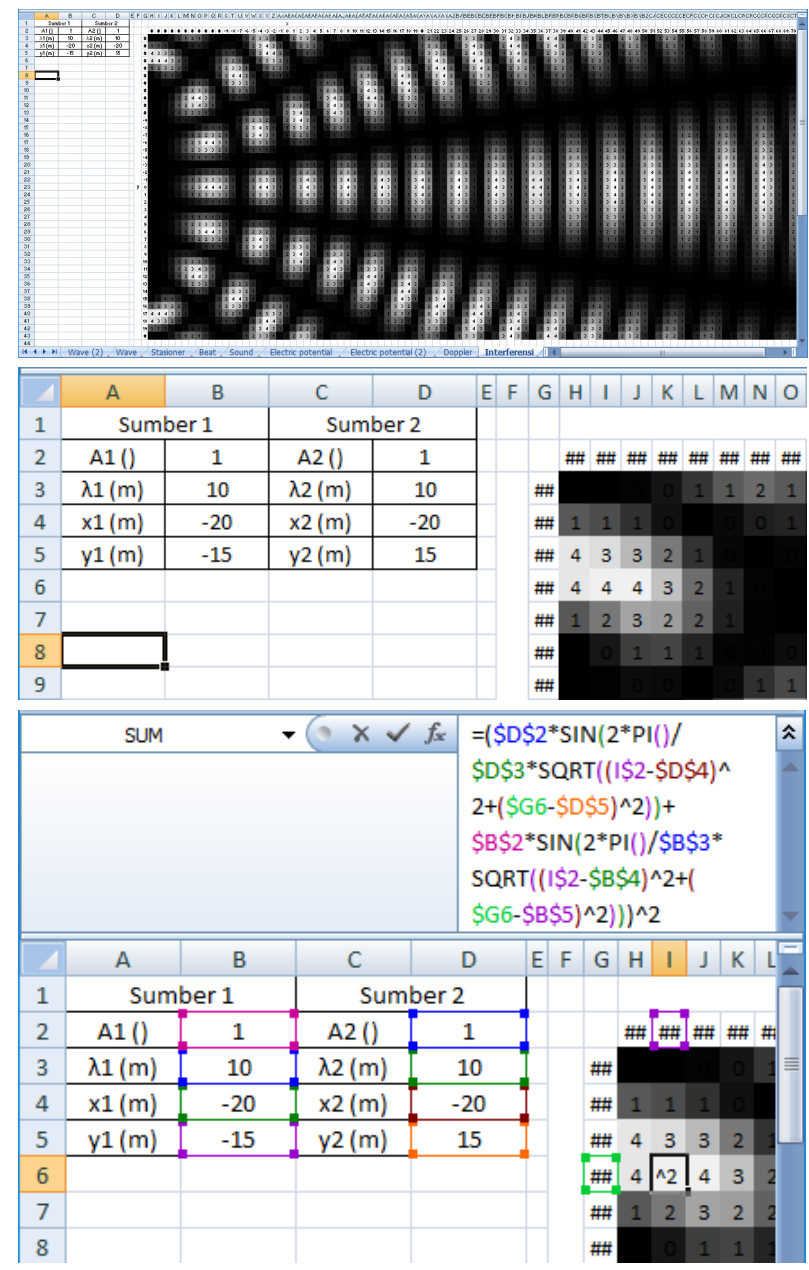

Gambar 13. Interferensi oleh dua celah: intensitas hasil interferensi dengan fitur conditional formatting putih-hitam (atas) parameter-parameter fisis yang digunakan (tengah), dan formula yang digunakan (bawah).

Dengan menggunakan sebuah spreadsheet, e.g. Microsoft Excel, interferensi pada setiap posisi dapat digam-

barkan, tidak hanya dilayar. Figur yang digunakan adalah referensi sel statis (dengan \$) dan dinamis (tanpa \$) serta conditional formatting seperti dalam Gambar 8. Hasil yang diperoleh dengan memanfaatkan fitur-fitur tersebut telah disajikan dalam Gambar 13. Sel yang tersorot adalah sel 16 yang isinya adalah

$=\left(\$ D \$ 2 * \operatorname{SIN}\left(2 * \mathrm{PI}() / \$ D \$ 3 * S Q R T\left((I \$ 2-\$ D \$ 4)^{\wedge} 2+(\$ G 6-\right.\right.\right.$ $\left.\left.\$ D \$ 5)^{\wedge} 2\right)\right)+\$ B \$ 2 * \operatorname{SIN}(2 * P I() / \$ B \$ 3 * \operatorname{SQRT}((I \$ 2-$

$\left.\left.\left.\$ B \$ 4)^{\wedge} 2+(\$ G 6-\$ B \$ 5)^{\wedge} 2\right)\right)\right)^{\wedge} 2$

yang tak lain merupakan ungkapan dari persamaan

$$
\begin{aligned}
& I(x, y)=\left[A_{1} \sin \left(\frac{2 \pi}{\lambda_{1}} \sqrt{\left(x-x_{1}\right)^{2}+\left(y-y_{1}\right)^{2}}\right)\right. \\
& \left.+A_{2} \sin \left(\frac{2 \pi}{\lambda_{2}} \sqrt{\left(x-x_{2}\right)^{2}+\left(y-y_{2}\right)^{2}}\right)\right]^{2},
\end{aligned}
$$

yang menggambarkan superposisi dari gelombang yang bersumber dari $\left(x_{1}, y_{1}\right)$ dan $\left(x_{2}, y_{2}\right)$. Sebagai konfirmasi Gambar 14 memberikan hasil pengamatan interferensi dua celah sempit (Narag, 2016), yang dalam sumber tersebut digunakan sebagai ilustrasi.

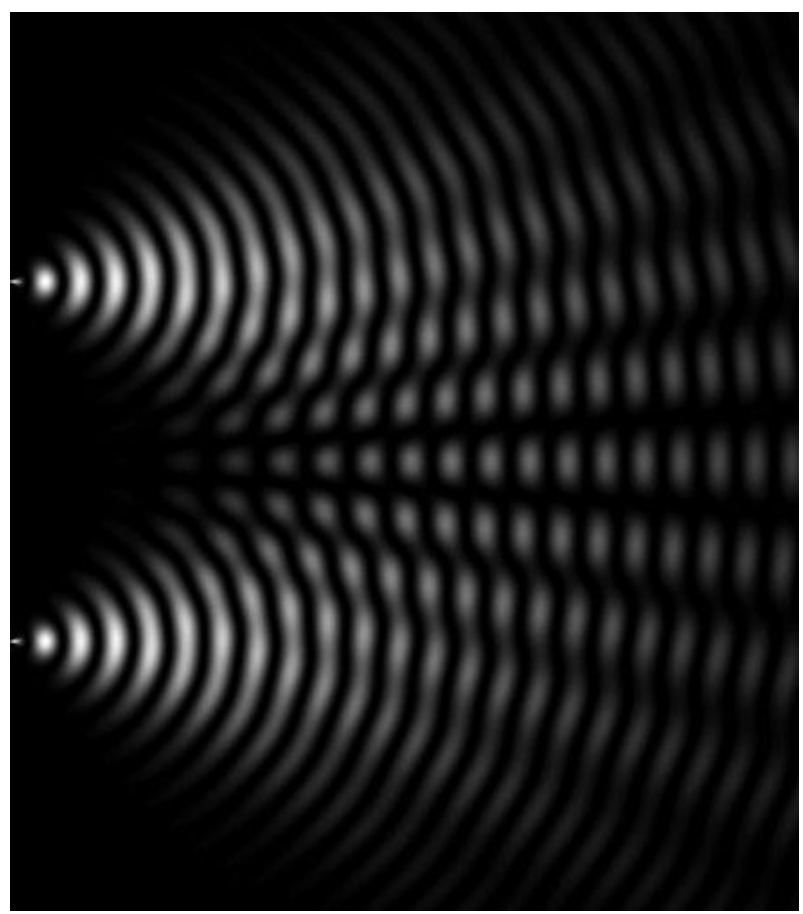

Gambar 14. Hasil interferensi oleh dua celah sempit.

Lalu bagaimana dengan lebih banyak sumber? Untuk $N$ buah sumber Persamaan (17) dapat dibuah menjadi lebih umum menjadi

$$
I(x, y)=\left[\sum_{i=1}^{N} E_{i}(x, y)\right]^{2}
$$

dengan

$$
E_{i}(x, y)=A_{i} \sin \left[\frac{2 \pi}{\lambda_{i}} \sqrt{\left(x-x_{i}\right)^{2}+\left(y-y_{i}\right)^{2}}\right]
$$

menggambarkan gelombang pada posisi $(x, y)$ akibat sumber yang berada pada posisi $\left(x_{i}, y_{i}\right)$.

Selanjutnya adalah menggunakan informasi yang diberikan oleh sel-sel spreadsheet dalam Gambar 13 
untuk menunjukkan keberlakukan Persamaan (15) dan (16) yang telah lebih umum dikenal. Dengan mengambil suatu kolom dari sel-sel dalam rentang \$H \$ 3 \$DI\$43 dapat diperoleh nilai dan tampilan dalam Gambar 15.

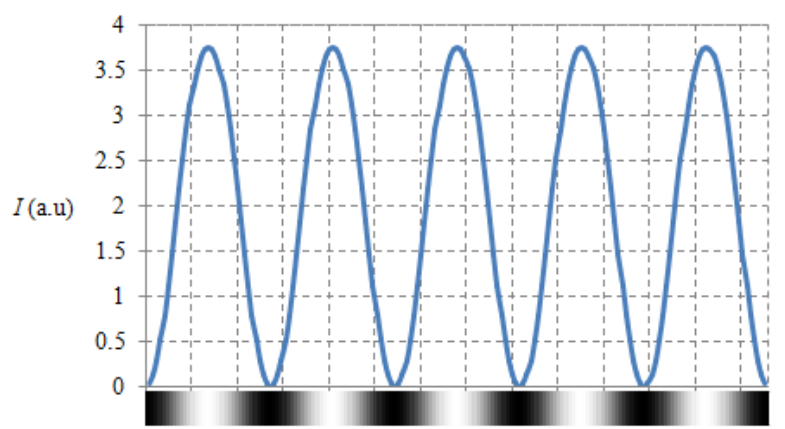

Gambar 15. Ilustrasi intesitas hasil interferensi dua celah sempit (sumber titik) dengan mengambil satu kolom sel-sel dari \$DE\$3 sampai \$DE\$43.

Dari kolom sel-sel yang diambil, untuk Gambar 15 adalah\$DE\$3:\$DE\$43 hanya diperoleh satu maksimum dan dua minimum yang mengapitnya. Puncak-puncak lain diperoleh dengan menduplikasinya.

Soal 8. Tunjukkan bahwa dengan mengambil kolom lain gambar seperti Gambar 15 dapat diperoleh.

Dengan membandingkan hasil yang diperoleh pada kolom-kolom yang berbeda, akan dapat ditunjukkan secara numerik bahwa Persamaan (15) dan (16) berlaku apabila jarak layar cukup jauh dari kedua celah (sumber) atau

$$
d<<L,
$$

dengan $d$ adalah jarak antar kedua celah dan $L$ adalah jarak layar ke celah, yang tak lain akan membawa ke pendekatan sudut kecil

$$
\sin \theta \approx \tan \theta .
$$

Soal 9. Tunjukkan bagaimana Persamaan (20) dapat membuat Persamaan (21). Gunakan aproksimasi dengan menggunakan deret Taylor atau Maclaurin bila diperlukan.

Bentuk $\sqrt{\left(x-x_{i}\right)^{2}+\left(y-y_{i}\right)^{2}}$ yang terdapat dalam Persamaan (17) atau (19) terdapat pula dalam perhitungan potensial listrik dan gravitasi oleh sumber titik dan juga perhitugan intensitas bunyi. Dengan demikian rumusan yang sama dapat diterapan untuk memperoleh ilustasin $V(x, y)$ untuk potensia listrik atau gravitasi dan $I(x, y)$ untuk intensitas bunyi.

Soal 10. Buatlah suatu sheet tambahan dalam spreadsheet yang telah diberikan sehingga potensial gravitasi $V_{G}(x, y)$, potensial listrik $V_{E}(x, y)$, dan intensitas bunyi $I(x, y)$ pada setiap posisi $(x, y)$ dapat digambarkan.

Telah ditunjukkan bahwa dengan menggunakan HTML dan JS serta spreadsheet telah dapat dirancang soalsoal dinamis materi fisika serta visualisasinya yang dapat membuat pengajar lebih fokus pada jenis soal dan mekanisme penyelesaiannya ketimbang perhitungan numeriknya. Dan tentu saja keefektifan pembelajaran dengan materi berbantuan HTML+JS dan spreadsheet ini masih perlu diobservasi menggunakan satu penelitian tindakan kelas (PTK).

Cresser JD 2005 "Wave Mechanics Notes for PHYS201", MacQuarie University, Sydney, 23 May, p. 11.

Botet R, Trizac E 2005 Eur. J. Phys. 26 S1.

Esquembre F 2002 Comput. Phys. Educ. 14713.

Flanagan D 2011 JavaScript: The Definitive Guide, O'Reilly Media Inc., 6th edn, p. 1.

Fowler M 2009 "The Doppler Effect" University of Virginia, Virginia, USA, 14 Oct, URL http://galileo.phys.virginia.edu /classes/152.mf1i.spring02/DopplerEffect.pdf [20171207].

Gatto SL, Tak SH 2008 Educ. Gerontol. 34800.

Griffiths M 200 Cyberpsychol. Behav. 3211.

Leonop DA, Suhendra A 2011 "Pemrograman Java Script untuk Simulasi Pada Aplikasi E-Learning Fisika Mekanika" karya tulis tingkat sarjana muda, Universitas Gunadarma, URL http://library.gunadarma.ac.id/repository/view/6156 [20171206].

Nafis N 2015 "Media Pembelajaran Fisika Berbasis Spreadsheet Excel Untuk Meningkatkan Prestasi Belajar Siswa" Prosiding Seminar Nasional Pendidikan Sains UKSW, 19 September, Salatiga, Indonesia, p. 280.

Narag MJ 2016 "Interference and Difraction" 28 February, URL https://jeremynarag.wordpress.com/2016/02/28/in terference-and-diffraction/ [20171207].

Nave CR 2016a "Displacement and Pressure" HyperPhysics, URL http://hyperphysics.phy-astr.gsu.edu/hbase/Waves /standw.html [20171206].

Nave CR 2016b "Double Slit Interference" HyperPhysics, URL http://hyperphysics.phyastr.gsu.edu/hbase/phyopt/slits.html [20171212].

Nuroso H, Arifin A 2011 JP2F 278.

Redish E 1993 Comput. Phys. 7613.

Takács G, Rohal'-Ilkiv B 2012 Model Predictive Vibration Control, Springer-Verlag London, p. 28.

Patel K 2014 "Standing Waves on a String / Ring" Physics Bridge Course, 3 May, URL https://physicsbridgecourse.blog spot.co.id/2014/05/standing-waves-on-string-ring.html [20171206].

Valiati ERdA, Heineck R 2002 "Computers in Teaching-Learning of Physics Discipline: Investigating Different Methodologies" Proceedings of the International Conference on Computers in Education (ICCE'02), 3-6 December 2002, Auckland, New Zealand, New Zealand.

Viridi S, Haryanto F, Purnama FA 2017a "Teach Yourself Fluid Concepts: How to Use Internet Resources" Pembelajaran Fisika, 30 Oktober 2017, doi: 10.17605/OSF.IO/85SAF.

Viridi S, Halid J, Kristianti T, Setiawan R 2017b "Penelitian Guru untuk Mempersiapkan Generasi Z di Indonesia" Seminar Penelitian Bidang IPA, 7-8 November 2017, Bandung, Indonesia, doi: 10.17605/OSF.IO/9TRA7.

Wikipedia 2017a "List of Office Suites" Wikipedia, The Free Encyclopedia, 24 November 15:08 UTC, oldid: 811868351 [20171206].

Wikipedia 2017b "Web Browser" Wikipedia, The Free Encyclopedia, 13 November 06:40 UTC, oldid: 810078891 [20171206].

Wikipedia 2017c "Speed of sound" Wikipedia, The Free Encyclopedia, 20 November 2017, 03:21 UTC, oldid: 811200578 [20171207].

Wikipedia 2017d, "Snell's law", Wikipedia, The Free Encyclopedia, 6 November 2017, 17:51 UTC, oldid: 809023371 [20171207]. 